\title{
Study of role of Magnesium sulfate in prevention of eclampsia
}

\author{
Shrinivas N. Gadappa, Pratibha V. Dixit*
}

Department of Obstetrics and Gynecology, Government Medical College Aurangabad, Maharashtra, India

Received: 27 September 2017

Accepted: 30 October 2017

\author{
*Correspondence: \\ Dr. Pratibha V. Dixit, \\ E-mail: dr.pratibha.dixit@gmail.com
}

Copyright: (c) the author(s), publisher and licensee Medip Academy. This is an open-access article distributed under the terms of the Creative Commons Attribution Non-Commercial License, which permits unrestricted non-commercial use, distribution, and reproduction in any medium, provided the original work is properly cited.

\begin{abstract}
Background: Hypertensive disorders of pregnancy have a clinical spectrum ranging from non-severe to severe preeclampsia and then potentially to eclampsia. Magnesium sulfate is drug of choice for women with eclampsia and now adapted for prophylaxis of seizures in women with preeclampsia.

Methods: It is randomized clinical trial, including 876 patients with preeclampsia fulfilling inclusion criteria. Patients with severe preeclampsia received anticonvulsant prophylaxis with magnesium sulfate. Patients with non-severe preeclampsia were randomized in two groups study group and control group. Patients in study group had received anticonvulsant prophylaxis with magnesium sulfate. The data obtained was analyzed with respect to maternal and perinatal outcome, severity of disease progression and adverse reactions of magnesium sulphate in each group.

Results: In this study statistically, significant difference was seen with respect to severity of disease progression and incidence of eclampsia among study and control group.

Conclusions: Administration of Magnesium sulfate in patients with non-severe preeclampsia does not affect the progress of labour or perinatal outcome, on contrary it improves maternal outcome by reducing incidence of eclampsia and progression of disease, without significant side effect of drug.
\end{abstract}

Keywords: Anticonvulsant, Eclampsia, Hypertensive disorders of pregnancy

\section{INTRODUCTION}

Hypertensive disorders are among the leading cause of morbidity and mortality in pregnancy. In India, eclampsia is the second most common cause of maternal mortality. ${ }^{1}$ Preeclampsia is a multisystem disorder of pregnancy usually associated with raised blood pressure and proteinuria, complicates about $2-8 \%$ of pregnancies. ${ }^{2}$ Eclampsia is defined as the occurrence of one or more convulsions superimposed on preeclampsia, which cannot be attributed to other cause. In developing countries, it affects around 1 in 100 to 1 in 1700 deliveries.

In developed it affects around 1 in 2000 deliveries. $^{2}$ Eclampsia is preventable by careful observation and prompt delivery when severe preeclampsia is present.
Magnesium sulfate is drug of choice for women with eclampsia for control of convulsions. Magnesium sulfate had central anticonvulsant activity by inhibiting the Nmethyl-D-aspartate receptor in brain. ${ }^{3}$ In this study we compared maternal and perinatal outcome in preeclampsia patients who had received and who had not received seizure prophylaxis with magnesium sulfate.

\section{METHODS}

It is randomized clinical trial conducted at Department of Obstetrics and Gynecology Government Medical College, Aurangabad, Maharashtra after getting clearance from Institutional Ethical Committee and scientific committee. 


\section{Inclusion criteria}

Pregnant patient coming to labour room included in study if

- Their blood pressure was equal to or more than 140 $\mathrm{mmHg}$ systolic (SBP) or equal to or more than 90 $\mathrm{mmHg}$ diastolic (DBP), on at least two occasions

- Have proteinuria of at least $1+$ on dipstick.

Depending upon the severity of preeclampsia, they were further divided into 2 groups, A and B as follows:

Group A: This group includes patients with non-severe preeclampsia, defined when SBP equal to or more than $140 \mathrm{mmHg}$ but less than $160 \mathrm{mmHg}$ and DBP equal to or more than $90 \mathrm{mmHg}$ but less than $110 \mathrm{mmHg}$ and not associated with any of the following:

- Frontal headache

- Clonus

- Visual disturbance

- Epigastric pain

- Pain in right upper abdominal quadrant

- Oliguria

- Pulmonary edema

- $\quad$ Elevated liver enzyme (SGOT, SGPT >40 IU/L)

- Increased serum creatinine $>1.5 \mathrm{mg} / \mathrm{Dl}$

- Evidence of hemolysis

- Thrombocytopenia.

Group B: This group includes all women of severe preeclampsia defined as $\mathrm{SBP} \geq 160 \mathrm{mmHg}$ and $\mathrm{DBP} \geq 110$ $\mathrm{mmHg}$ and associated with any of the above (1-11) feature.

These patients had received magnesium sulfate prophylaxis and not divided in any subgroup. Patients of non-severe preeclampsia included in group A are further randomized in to subgroups to receive magnesium sulfate prophylaxis as:
- Group A1: This subgroup includes all those women with non-severe preeclampsia who had received magnesium sulfate prophylaxis and labeled as study group.

- Group A2: This subgroup includes all those women of non-severe preeclampsia who had not received magnesium sulfate prophylaxis and labeled as control group.

Injection Magnesium sulfate was administered to patient as per Pritchard regime. ${ }^{9}$

\section{Exclusion criteria}

Patients excluded from study that have any of the following

- Hepatic coma with risk of renal failure,

- Myasthenia gravis

- Associated medical disorder (anemia, heart disease, epilepsy, asthma, thyroid disorder etc).

Data obtained was analyzed using chi square test.

\section{RESULTS}

The study role of Magnesium sulfate in prevention of eclampsia was carried out in department of obstetrics and gynaecology GMCH Aurangabad for a period of two years. During this period 22,881 deliveries took place. Among these 1,346 patients had preeclampsia so, the incidence was $5.88 \%$. Out of these 1,346 patients 470 had other associated medical disorder hence excluded from the study.

Thus 876 patients with preeclampsia were studied. During the study period 429 patients had eclampsia so incidence was $1.87 \%$. The baseline characteristics of patients who were included are shown below. The average age of distribution in all three groups was 22.73 year. As shown in Table 1, majority of patients in study were primigravidae.

Table 1: The distribution of patients based on parity index.

\begin{tabular}{|c|c|c|c|c|c|c|c|}
\hline \multirow{3}{*}{ Parity } & \multirow{2}{*}{\multicolumn{2}{|c|}{ Severe preeclampsia }} & \multicolumn{4}{|c|}{ Non-severe preeclampsia } & \multirow{3}{*}{ Total } \\
\hline & & & \multicolumn{2}{|c|}{ Study group } & \multicolumn{2}{|c|}{ Control group } & \\
\hline & Number & $\%$ & Number & $\%$ & Number & $\%$ & \\
\hline Primigravidae & 216 & 60.67 & 168 & 65.62 & 182 & 68.93 & 566 \\
\hline Multigravida & 140 & 39.32 & 88 & 34.37 & 82 & 31.06 & 310 \\
\hline Total & 356 & 100 & 256 & 100 & 264 & 100 & 876 \\
\hline
\end{tabular}

Near about half of the patients $(48.05 \%)$ in the three groups were ANC registered. As shown in Table 2, out of 876 patients, $755(86.18 \%)$ were $37-40$ weeks of gestational age and mean gestational age was 37.92 weeks. Maximum gestational age observed was 43 weeks, seen in two patients; both had non-severe preeclampsia and were not having any ANC visit before. Minimum gestational age was 26 weeks. At the time of admission all three patients were having intrauterine foetal demises. 
As shown in Table 3, associated pregnancy complications were present in 240 patients $(27.3 \%)$ and most common complication was intrauterine growth restriction present in 168 patients $(19.17 \%)$.

Table 2: The distribution of patients based on their gestational age at which they were included in the study.

\begin{tabular}{|c|c|c|c|c|c|c|c|}
\hline \multirow{3}{*}{$\begin{array}{l}\text { Gestational age in } \\
\text { weeks }\end{array}$} & \multirow{2}{*}{\multicolumn{2}{|c|}{ Severe preeclampsia }} & \multicolumn{4}{|c|}{ Non-severe preeclampsia } & \multirow{3}{*}{ Total } \\
\hline & & & \multicolumn{2}{|c|}{ Study group } & \multicolumn{2}{|c|}{ Control group } & \\
\hline & Number & $\%$ & Number & $\%$ & Number & $\%$ & \\
\hline $26-33$ & 23 & 6.46 & 4 & 1.56 & 7 & 2.65 & 34 \\
\hline $34-36$ & 21 & 5.89 & 6 & 2.34 & 11 & 4.16 & 38 \\
\hline $37-40$ & 303 & 85.11 & 222 & 86.71 & 230 & 87.12 & 755 \\
\hline 41 weeks $\geq$ & 9 & 2.52 & 24 & 9.37 & 16 & 6.06 & 49 \\
\hline Total & 356 & 100 & 256 & 100 & 264 & 100 & 876 \\
\hline
\end{tabular}

Table 3: The distribution of patients based on associated pregnancy complication.

\begin{tabular}{|c|c|c|c|c|c|c|c|}
\hline \multirow{3}{*}{$\begin{array}{l}\text { Associated } \\
\text { pregnancy } \\
\text { complication }\end{array}$} & \multirow{2}{*}{\multicolumn{2}{|c|}{ Severe preeclampsia }} & \multicolumn{4}{|c|}{ Non-severe preeclampsia } & \multirow{3}{*}{ Total } \\
\hline & & & \multirow{2}{*}{$\begin{array}{l}\text { Study group } \\
\text { Number (\%) }\end{array}$} & & \multicolumn{2}{|l|}{ Control group } & \\
\hline & Number (\%) & $\%$ & & $\%$ & Number (\%) & $\%$ & \\
\hline IUGR & $122(34.26)$ & 64.21 & $24(9.37)$ & 92.3 & $22(8.33)$ & 91.6 & 168 \\
\hline IUFD & $33(9.26)$ & 17.36 & 0 & 0 & $1(0.37)$ & 4.16 & 34 \\
\hline Abruptio placentae & $17(4.77)$ & 8.94 & 0 & 0 & 0 & 0 & 17 \\
\hline Partial HELLP & $12(3.37)$ & 6.31 & 0 & 0 & 0 & 0 & 12 \\
\hline Oligohydramnios & $3(0.84)$ & 1.57 & $2(0.78)$ & 7.69 & $1(0.37)$ & 4.16 & 6 \\
\hline HELLP & $3(0.84)$ & 1.57 & 0 & 0 & 0 & 0 & 3 \\
\hline Total & $190(53.37)$ & 100 & $26(10.15)$ & 100 & $24(9.09)$ & 100 & $240(27.3)$ \\
\hline
\end{tabular}

\section{Observation for disease progression and maternal deaths}

Out of 876 patients 41 progressed to eclampsia (4.68\%). In group B out of 356 patients $16(4.68 \%)$ had eclampsia. In group A incidence of eclampsia was 3 out of 256 $(1.17 \%)$ in study group as compared to 22 in $264(8.33 \%)$ in control group. the difference was statistically significant ( $\mathrm{p}$ value was 0.0001 ).

Table 4: Patient distribution on the basis of progression of disease in patients with severe preeclampsia (Group B).

\begin{tabular}{|lll|}
\hline $\begin{array}{l}\text { Progression of } \\
\text { disease }\end{array}$ & $\begin{array}{l}\text { Number of } \\
\text { patients }(\%)\end{array}$ & Percentage \\
\hline $\begin{array}{l}\text { Placental abruption } \\
7(1.96)\end{array}$ & 31.81 \\
\hline Acute renal failure & $6(1.68)$ & 27.27 \\
\hline Partial HELLP & $4(1.12)$ & 18.18 \\
\hline $\begin{array}{l}\text { Pulmonary oedema } \\
\text { Disseminated } \\
\text { intravascular } \\
\text { coagulation }\end{array}$ & $3(0.84)$ & 13.63 \\
\hline $\begin{array}{l}\text { Acute fatty liver of } \\
\text { pregnancy }\end{array}$ & $1(0.28)$ & 4.54 \\
\hline Total & $22(0.28)$ & 4.54 \\
\hline
\end{tabular}

As shown in Table 4 most common complication was abruption placentae in $31.81 \%$ followed by acute renal failure. Out of 6 cases of ARF, three had abruption also but all patients recovered. One patient of ARF required peritoneal dialysis but expired. Out of 6 patients who developed ARF, three expired.

As shown in Table 5 in study group out of 256 patients, $17(6.64 \%)$ progressed to severe disease as compared to $37(14.01 \%)$ in control group and the difference was statistically significant $(\mathrm{p}=0.005)$. In study group only one patient developed placental abruption as compared to 11 in control group and the difference was statistically significant $(\mathrm{p}=0.003)$.

Out of 876 patients 5 died $(0.57 \%)$ during the study period. there were 4 maternal deaths in group B, no maternal death was observed in study group (A1), and one patient died in control group (A2).

\section{Observation for adverse effects and toxicity of Magnesium sulfate}

As shown in Table 6, among all patients who received inj. Magnesium sulfate, $33.33 \%$ developed some adverse reaction. Respiratory depression was noted in 9 women and all responded to nasal oxygen and Calcium gluconate intravenous injection. Out of 9 cases of respiratory depression, 8 were noted during reversal of general anaesthesia given for LSCS. One patient reported it immediately after delivery. 
Table 5: Patient distribution on the basis of progression of disease in patients with non- severe preeclampsia (group A).

\begin{tabular}{|c|c|c|c|c|c|}
\hline \multirow{3}{*}{ Progression of disease } & \multicolumn{4}{|c|}{ Non-severe preeclampsia } & \multirow{3}{*}{ Total } \\
\hline & \multicolumn{2}{|c|}{ Study group $\mathbf{N}=256$} & \multicolumn{2}{|c|}{ Control group N=264 } & \\
\hline & Number $(\%)$ & $\%$ & Number $(\%)$ & $\%$ & \\
\hline Severe preeclampsia & $17(6.64)$ & 94.44 & $37(14.01)$ & 68.51 & $54(10.38)$ \\
\hline Abruption placentae & $1(0.39)$ & 5.55 & $11(4.16)$ & 20.37 & $12(2.30)$ \\
\hline Acute renal failure & 0 & 0 & $3(1.13)$ & 5.55 & $3(0.57)$ \\
\hline Pulmonary oedema & 0 & 0 & $1(0.37)$ & 1.85 & $1(0.19)$ \\
\hline $\begin{array}{l}\text { Disseminated intravascular } \\
\text { coagulation }\end{array}$ & 0 & 0 & $1(0.37)$ & 1.85 & $1(0.19)$ \\
\hline Eclampsia coma & 0 & 0 & $1(0.37)$ & 1.85 & $1(0.19)$ \\
\hline Total & $18(7.03)$ & 100 & $54(20.45)$ & 100 & $72(13.84)$ \\
\hline
\end{tabular}

Table 6: Distribution of side effects and adverse effects of magnesium sulfate.

\begin{tabular}{|c|c|c|c|c|c|}
\hline \multirow{3}{*}{ Adverse effects } & \multirow{2}{*}{\multicolumn{2}{|c|}{ Severe preeclampsia $(\mathrm{N}=356)$}} & \multicolumn{2}{|c|}{ Non-severe preeclampsia } & \multirow{3}{*}{ Total } \\
\hline & & & \multicolumn{2}{|c|}{ Study group $(\mathbf{N}=256)$} & \\
\hline & Number (\%) & $\%$ & Number & $\%$ & \\
\hline Flushing & $48(13.48)$ & 41.02 & $34(13.28)$ & 39.08 & $82(13.39)$ \\
\hline Pain at injection site & $24(6.74))$ & 20.52 & $27(10.54)$ & 31.03 & $51(8.33)$ \\
\hline Hypotension & $28(7.86)$ & 23.93 & $22(8.59)$ & 25.28 & $50(8.16)$ \\
\hline Respiratory depression & $6(1.68)$ & 5.12 & $3(1.17)$ & 3.44 & $9(1.47)$ \\
\hline Absent reflexes & $5(1.40)$ & 4.27 & $1(0.39)$ & 1.14 & $6(0.98)$ \\
\hline $\mathrm{ARF}$ & $6(1.68)$ & 5.12 & 0 & 0 & $6(0.98)$ \\
\hline Total & $117(32.86)$ & $100 \%$ & 87 (33.98) & 100 & $205(33.33)$ \\
\hline
\end{tabular}

Table 7: Distribution of patients on the basis of cause for omission of magnesium sulfate.

\begin{tabular}{|llllll|}
\hline \multirow{2}{*}{ Adverse effects } & \multicolumn{2}{l}{$\begin{array}{l}\text { Severe preeclampsia } \\
\text { (N=356) }\end{array}$} & \multicolumn{2}{l}{ Son-severe preeclampsia } \\
& Number $(\boldsymbol{\%})$ & $\%$ & Number $(\boldsymbol{\%})$ & $\%$ & Total \\
\hline Respiratory depression & $6(1.68)$ & 35.2 & $3(1.17)$ & 75 & $9(42.85)$ \\
\hline Absent reflexes & $5(1.40)$ & 29.4 & $1(0.39)$ & 25 & $6(28.57)$ \\
\hline ARF & $6(1.68)$ & 35.2 & 0 & 0 & $6(28.57)$ \\
\hline Total & $17(4.77)$ & $100 \%$ & $4(1.56)$ & 100 & $21(3.43)$ \\
\hline
\end{tabular}

Magnesium sulfate was omitted in $21(3.43 \%)$ patients and 17 out of 21 were in group B (severe preeclampsia) and the difference was not statistically significant $(\mathrm{p}>0.05)$.

\section{Observation for labour characteristics, mode of delivery}

Out of 876 patients in trial $711(81.16 \%)$ delivered vaginally. In patients with severe preeclampsia vaginal delivery was observed in 276 patients (77.52\%). In 256 patients in study group $46(17.96 \%)$ delivered by LSCS as compared to $49(18.56 \%)$ in 264 controls and the difference was statistically not significant. There was no statistically significant difference in duration of labour in study and control group ( $\mathrm{p}=0.58)$. Out of 876 patients, $102(11.64 \%)$ required blood transfusion. In study group (group A1) 18 patients $(7.03 \%)$ required blood transfusion as compared to 36 patients (13.63\%) in control group and the difference was statistically significant $(\mathrm{p}=0.01)$.

\section{Observation for perinatal outcome}

Out of 900 babies born in the study, 747 were live birth. In study group $254(96.57 \%)$ babies were live birth out of 263 babies as compared to $257(94.13 \%)$ out of 273 in controls. There was no statistically significant difference between two groups with respect to Apgar score at 1 minute and 5 minutes, NICU admission and neonatal deaths.

\section{DISCUSSION}

As per the National eclampsia registry, it is estimated that almost 72000 women die of preeclampsia and eclampsia related problems. While the incidence in India is approximately $10 \%$, the global estimates are similar. Magnesium sulfate is the drugs of choice for seizure prophylaxis in patients of severe pre-eclampsia. In the present study all patients with severe preeclampsia received Magnesium sulfate. Patients with non-severe 
preeclampsia divided in to study group and control group. In study group all patients received seizure prophylaxis with inj. Magnesium sulfate as per Pritchard regime. The incidence of preeclampsia was $5.88 \%$.

\section{Characteristics of patients in the study}

The mean age of all patients in the present study was 22.7 year. In group of severe preeclampsia, it was 23 years and is comparable to that observed in the study by Atkinson. ${ }^{4}$ The mean age was less than that observed in the studies of Moodley and Moodley, Magpie trial and Dayicioglu et al. ${ }^{2,5,6}$ This variation in the mean age may be explained by the early marriage and early onset of reproductive life in India. In non-severe preeclampsia group the mean age in our study is comparable to that observed in the study of Livingston et al. ${ }^{7}$ The percentage of primigravidae in the present study was $64.61 \%$, and is comparable to that observed in study of Atkinson et al. ${ }^{4}$ The mean gestational age of patients in study and control group was respectively 38.38 and 38.09 weeks which was comparable to that observed in the randomized control trial in women with mild preeclampsia by Livingston et al. ${ }^{7}$

\section{Comparison of associated pregnancy complication}

In the present series, IUGR is observed in women with severe preeclampsia in $34.26 \%$, and is more than twice as compared to that observed by Dayicioglu et al. ${ }^{6}$ This difference is explained because high proportion of unregistered pregnancies in the present study in whom early onset preeclampsia remain unnoticed and resultant IUGR come into picture when patient reported during labour at our hospital. In the present study $9.26 \%$ patients had IUFD that was similar to what observed by Dayicioglu that is $7 \% .{ }^{6}$ HELLP syndrome was observed in the present study in $4.21 \%$ women with severe preeclampsia which was lower than that observed in study of Moodley and Moodley and Dayicioglu et al that was $8 \%$ and $7.7 \%$ respectively. ${ }^{5,6}$ In patients with severe preeclampsia received Magnesium sulfate prophylaxis, incidence of eclampsia was $4.49 \%$ and it was comparable to that observed by Dayicioglu et al in their study, which was $3.62 \% .^{6}$ Reti, Girard et al and Singh et al in their studies of severe preeclampsia treated with magnesium sulfate did not notice eclampsia in their patients. ${ }^{8-10}$

Alexander et al studied the incidence of eclampsia in patients with non-severe preeclampsia when only patients with severe preeclampsia were given magnesium sulfate prophylaxis. ${ }^{11}$ They observed that the overall incidence of eclampsia was increased by around $50 \%$ as compared to previous 5-year record when every patient with preeclampsia was receiving magnesium sulphate.

In the present study patients with non-severe preeclampsia in study group incidence of eclampsia was $1.17 \%$ as compared to $8.33 \%$ in control group. This difference is statistically highly significant $(\mathrm{p}=0.0001)$.
This implies that there is a significant association of not having eclampsia with magnesium sulfate prophylaxis. Among patients of non-severe preeclampsia, the incidence of placental abruption was lower in the study group as compared to controls, $0.3 \%$ versus $4.16 \%$ $(\mathrm{p}=0.003)$. This was similar to that observed in the Magpie trial. ${ }^{2}$

Acute renal failure was observed in $1 \%$ of patients in the present study, similar result was observed by Magpie trial that is ARF was noted in $1 \%$ patients in study group and $1.2 \%$ in control group. ${ }^{2}$ In the present study maternal mortality was $0.57 \%$ in severe preeclampsia patients which was slightly higher than that observed in the Magpie trial, where it was $0.2 \%$ in study group and $0.4 \%$ in control group. ${ }^{2}$ In non-severe preeclampsia group no death was reported in study group but it was $0.27 \%$ in control group. No maternal death was reported by Moodley and Moodley and Livingston et al in their study. 5,7

\section{Comparison of adverse effects of drug and indications for omission of drug}

In the present study adverse effects of drug were observed in $33.33 \%$ of patients. Incidence of flushing observed in the present study was $13.39 \%$ and is less than that observed in Magnesium sulfate group in Magpie trial, which was $19.74 \% .^{2}$ Respiratory depression was observed in the present study in $1.47 \%$ of patients and is slightly higher than $1.02 \%$ as observed in the Magpie trial. ${ }^{2}$ Absent reflexes was observed in $0.98 \%$ in the present study which was less than $1.18 \%$ as noted in the Magpie trial. ${ }^{2}$ In the present study $3.43 \%$ of women magnesium sulfate treatment was stopped which is much less than $16 \%$ as observed in the Magpie trial. ${ }^{2}$ In the present study most common indication for omitting magnesium sulfate was respiratory depression in $1.47 \%$ of patients which was slightly higher than $0.51 \%$ as observed in the Magpie trial. ${ }^{2}$

\section{Comparison of labour characteristics and perinatal outcome}

In the present study caesarean delivery was required in $18.84 \%$ of women with preeclampsia, which is much lower than $50 \%$ and $48 \%$ seen in the Magpie trial in study and control group respectively. ${ }^{2}$ The mean duration of labor in severe preeclampsia was 6.01 hours, which is less than half (13.7 hours) of that observed by Atkinson et al in 1995 and 12.5 hours in Magpie trial and also less than 10.9 hours as observed by Szal et al. , $^{2,12}$

The difference may be due to the reason that majority women in the present study came to hospital at the onset of labour. In severe preeclampsia, perinatal death was $23.35 \%$ which was comparable to $20.22 \%$ as observed by Sardesai et al, the perinatal mortality was $20.10 \%$ in the study of Dayicioglu et al and $17.09 \%$ as observed by Moodley and Moodley. ${ }^{1,5,6}$ 


\section{CONCLUSION}

In the present study, we observed that Magnesium sulfate administered to patients with non-severe preeclampsia is associated with statistically significant trend towards lower incidence of eclampsia and also disease progression. Also, there was no significant side effect of drug noted in those who received Magnesium sulfate and were very less as compared to other studies. There was no significant difference in duration of labour, incidence of LSCS and postpartum haemorrhage in both the study group and control group in women with mild preeclampsia in the present study. Perinatal outcome was also similar in study and control group. Hence, administration of Magnesium sulfate in patients with non-severe preeclampsia does not affect the progress of labour or perinatal outcome, on contrary it improves maternal outcome by reducing incidence of eclampsia and progression of disease, without significant side effect of drug.

Funding: No funding sources

Conflict of interest: None declared

Ethical approval: The study was approved by the Institutional Ethics Committee

\section{REFERENCES}

1. Sardesai S, Maira S, Patil A, Patil U. Low dose magnesium sulfate therapy for eclampsia and imminent eclampsia; Regime tailored for Indian women. J Obstet Gynecol India. 2003;53(6):540-6.

2. Altman D, Carroli G, Duley L, Farrell B, Moodley J, Neilson J, et al. Do women with preeclampsia and their babies benefit from magnesium sulfate? The Magpie trial: a randomized placebo trial. Lancet 2002;359:1877-90.

3. Cotton DB, Janusz CA, Berman RF. Anticonvulsant effect of magnesium sulfate on hippocampal seizures: therapeutic implications in preeclampsiaeclampsia. Am J Obstet Gynaecol. 1992;166:1127.

4. Atkinson MW, Guinn D, Owen J, Hauth JC. Does magnesium sulfate the length of labour induction in women with pregnancy associated hypertension? Am J Obstet Gynaecol. 1995:173;1219-22.

5. Moodley J, Moodley VV. Prophylactic anticonvulsant therapy in hypertensive crises of pregnancy: the need for a large randomized trial. 1994;13:245-52.

6. Dayicioglu V, Sahino Z, Kola E, Kucukbas M. The use of standard dose of magnesium sulfate in prophylaxis of eclamptic seizures: Do body mass index alterations have any effect on success? Hypertension in Pregnancy. 2003;22(3):257-65.

7. Livingston JC, Livingston LW, Ramsey R, Mabie BC, Sibai BM. Magnesium sulfate in women with mild preeclampsia: a randomized controlled trial. J Obst Gynecol. 2003;101:217-20.

8. Red LL, Ross A, Kloss M, Paull J, Markman L. The management of severe preeclampsia with intravenous magnesium sulphate, hydralazine and central venous catheterization. $\mathrm{Au} \mathrm{N} \mathrm{Z} \mathrm{J} \mathrm{Obstet}$ Gynaecol. 1987;27(2):102-5.

9. Girard B, Beucher G, Muris C, Simonet T, Dreyfus M. Magnesium sulfate and severe preeclampsia: its use in current practice. J Gynecol Obstet Biol Reprod. 2005;34:17-22.

10. Singh J, O'Donovan M, Coultersmith SD, Geary M. An audit of the use of magnesium sulphate in severe preeclampsia and eclampsia. J Obstet Gynecol 2005;25(1):15-7.

11. Alexander JM, McIntire DD, Leveno KJ, Cunningham FG. Selective magnesium sulfate prophylaxis for the prevention of eclampsia in women gestational hypertension. Obstet Gynecol. 2006;108(4):826-32.

12. Szal ES, Croughan-Minihane MS, Kilpatrick SJ. Effects of magnesium prophylaxis and preeclampsia on the duration of labor. Am J Obstet Gynecol. 1999;180:1475-9.

Cite this article as: Gadappa SN, Dixit PV. Study of role of Magnesium sulfate in prevention of eclampsia. Int J Reprod Contracept Obstet Gynecol 2017;6:5497-502. 